\title{
Fintech Di Era Digital Untuk Meningkatkan Kinerja ZIS di Indonesia
}

\author{
${ }^{1 *}$ Soeharjoto, ${ }^{2}$ Debbie Aryani Tribudhi, ${ }^{3}$ Lucky Nugroho \\ ${ }^{1,2}$ Fakultas Ekonomi dan Bisnis, Universitas Trisakti, Indonesia \\ ${ }^{3}$ Fakultas Ekonomi dan Bisnis, Universitas Mercu Buana, Indonesia \\ *Email korenpondensi: ryoto16@yahoo.com
}

\begin{abstract}
Purpose of this study is to predict trend value of collecting ZIS with fintech and non fintech. Data taken from BAZNAs from 2002-2017 and using descriptive statistics with linear trend and parabolic, inference statistic with paired sample test. Result shown that fintech trend like parabolic and non fintech like linear. There is a significant and power full correlation at ZIS revenue with fintech and non fintech. Thus, there is difference average of ZIS revenue before and after using fintech. Using SIMBA fintech will be affecting the revenue of ZIS. Average prediction of ZIS collecting funds from 2018-2025 with fintech is greater than using non fintech. Average growth of ZIS revenue with fintech is 9.98 percent and 5.78 percent with non fintech.
\end{abstract}

Keywords: ZIS, Fintech, SIMBA, BAZNAS

\begin{abstract}
Abstrak
Penelitian ini bertujuan untuk memprediksi nilai trend pengumpulan ZIS dengan menggunakan fintech dan non fintech. Metode yang digunakan statistik deskriptif dengan membuat trend linier dan parabola, serta statistik inferensia dengan paired sample test, dengan data yang berasal dari BAZNAS pada 2002-2017. Hasil penelitian menunjukkan bahwa trend fintech berbentuk parabola dan non fintech berbentuk linier. Penerimaan ZIS menggunakan fintech dan non fintech terdapat korelasi yang kuat dan signifikan. Dengan demikian, ratarata penerimaan ZIS sebelum dan sesudah menggunakan fintech adalah tidak sama (berbeda). Penggunaan fintech berupa SIMBA akan mempengaruhi jumlah penerimaan ZIS. Prediksi rata-rata dari pertumbuhan pengumpulan dana ZIS pada 2018-2025 dengan menggunakan fintech lebih besar dari pada non fintech. Ratarata pertumbuhan penerimaan ZIS dengan fintech sebesar 9,98 persen dan non fintech sebesar 5,78 persen.
\end{abstract}

Kata Kunci: ZIS, Fintech, SIMBA, BAZNAS

Saran Sitasi: Soeharjoto., Tribudhi, D., \& Santosa, L. (2019). Fintech Di Era Digital Untuk Meningkatkan Kinerja ZIS di Indonesia. Jurnal Ilmiah Ekonomi Islam, 5(03), 137-144. doi: http://dx.doi.org/10.29040/jiei.v5i3.529

DOI: http://dx.doi.org/10.29040/jiei.v5i3.529

\section{Pendahuluan}

Pasca era globalisasi, dengan semakin berkembangnya teknologi informasi, membuat dunia menjadi tanpa batas (Soeharjoto, 2016). Kondisi ini, ditunjang dengan adanya kemudahan atas bantuan teknologi yang merupakan peluang bagi negara untuk dapat maju lebih pesat lagi, terutama bagi umat Islam (Walter, 2004).
McKeon dan Weir (2000), mengungkapkan penggunaan ilmu pengetahuan dalam melakukan persaingan akan mempercepat kesejahteraan, karena adanya inovasi dalam pemanfaatan sumber daya, sehingga akan tercapainya efisiensi dan efektifitas. Namun demikian, apabila hanya mengandalkan pada ilmu pengetahuan saja dalam mengelola ekonomi akan terjadi 
kegagalan, karena mengabaikan aspek nilai sosial dan etika (Buarque, 1993). Ekonomi modern yang mengabaikan etika dan spiritual, merupakan suatu kesalahan fatal, karena manusia merupakan mahluk yang berperasaan dan berakal (Hamilton, 1994). Adanya fairness, dapat dijadikan sebagai sumber keadilan dan efisiensi dalam ilmu ekonomi (Rothchild, 1993). Chapra (2001), mengungkapkan adanya pendekatan mikro ekonomi tanpa memperhatikan makro ekonomi yang didasarkan pada pandangan dunia dan agama, hanya akan memikirkan kepentingan individu, dengan demikian dalam menjalankan ekonomi, sebaiknya juga mengunakan prinsip ekonomi Islam, karena dalam ekonominya bukan hanya terletak pada watak pelakunya saja, tetapi pada sistem yang harus dipedomani para pelaku ekonomi, yakni semua faktor ekonomi merupakan kepunyaan Allah dan kepada-Nya dikembalikan segala urusannya.

Indonesia merupakan negara dengan mayoritas penduduknya beragama Islam (Soekapdjo et. al, 2018). Jumlah penduduk yang banyak merupakan potensi yang besar dalam penggalangan dana Zakat (Romdhoni, 2017). Kewajiban membayar zakat bagi muslim di dalam Al Quran, telah disebut sebanyak 30 kali, yakni terdapat pada Surat Makiyah sebanyak 8 kata dan Surat Madaniyah sebanyak 22 kata. Anjuran zakat yang terdapat pada Surat At Taubah ayat 103 menyatakan bahwa "Ambilah zakat dari sebagian harta mereka, dengan zakat itu kamu membersihkan dan menyucikan mereka, dan berdoalah untuk mereka. Sesungguhnya doa kamu itu menjadi ketentraman jiwa bagi mereka. Dan Allah Maha Mendengar lagi Maha Mengetahui”. Namun, terdapat beberapa syarat harta yang dapat dijadikan objek zakat, yakni memenuhi syarat hartanya yang halal, dimiliki secara penuh, berkembang, cukup nisab dan haul, bebas dari hutang, dan merupakan kelebihan dari kebutuhan pokok. Ketetapan ini, menunjukkan bahwa zakat yang diberikan tidak membebani pihak yang memberikan zakat dan yang menerimanya juga akan mendapatkan keberkahan.
Zakat dalam ketentuannya terdapat dua jenis, yakni fitrah dan harta (maal) (Wahyuni dan Chintya, 2017). Zakat fitrah merupakan kewajiban bagi umat muslim pada bulan ramadhan yang pemberiannya sebelum sholat idul fitri dan zakat harta dapat dibayarkan pada waktu kapan saja. Dengan demikian, pengumpulan dana zakat dapat dilakukan sepanjang waktu. Zakat merupakan cara untuk mengurangi ketimpangan antara yang kaya dan miskin (Marimin dan Fitria, 2015). Dengan demikian, peruntukkan zakat dapat diberikan secara prioritas, sesuai dengan Surat At-Taubah ayat 8 yang diperuntukan bagi kaum fakir, Miskin, Amil, Mualaf, Rigab, Gharin, Fisabillilah dan Ibnu Sabil. Disamping itu, dapat juga diberikan dengan kondisi khusus, bagi mereka yang dalam kondisi tertentu dan membutuhkan pertolongan dan pemberdayaan dengan ketentuan memenuhi kriteria Mustahik.

Berkembangnya pengelolaan zakat di Indonesia, tidak terlepas dari adanya pihak yang menghimpun dana zakat, yang dilakukan oleh organisasi pengelola zakat (OPZ) (Marzuki dan Qomar, 2015). Untuk mengatur pengelolaan zakat, pemerintah mengeluarkan Peraturan Perundang-undangan No. 38 Tahun 1999, yang menyatakan bahwa pemerintah membagi dua jenis OPZ, yakni Badan Amil Zakat (BAZ) yang dibentuk pemerintah dan Lembaga Amil Zakat (LAZ) yang dibentuk masyarakat (Rahmawati, 2011). Kemudian, berkembang Undang-undang No. 23 Tahun 2011, yang menyatakan bahwa kedudukan BAZ dan LAZ berbeda. Setelah dikeluarkan undang-undang ini, OPZ mengalami pertumbuhan yang pesat, karena adanya faktor penarik dan pendorong (Karim dan Syarief, 2008). Faktor penariknya adalah spirit of consciousness, spirit of innovation, dan spirit of empowering. Faktor pendorongnya huge market potential, friendly regulation, IT Infrastructure, dan awareness increasing. OPZ sebagai lembaga publik, dalam melakukan aktivitasnya terkait dengan Undang-undang No. 14 tahun 2008, 
tentang keterbukaan informasi. Dengan demikian, OPZ dapat lebih akuntabel.

Keseriusan pemerintah dan masyarakat dalam mengalang dan umat tidak diragukan lagi. Adapun tindakannya dengan mengeluarkan Sistem Manajemen Informasi BAZNAS atau SIMBA pada Nonember 2011. Penggunaan Fintech ini sangat membantu perkembangan penggalangan umat. SIMBA memiliki dua sistem, yakni sistem informasi operasi (SIO) dan sistem informasi pelaporan (SIP). SIO digunakan BAZNAS dan LAZ untuk operasi sehari-hari dengan pendekatan kas masuk dan keluar. Kas masuk meliputi muzaki, transaksi penghimpun dana ZIS dan kas keluar meliputi data base mustahik dan penyaluran ZIS.

Perkembangan pengumpulan dana ZIS sangat pesat pasca diberlakukannya penggunaan financial technology (fintech). Rata-rata pertumbuhan ZIS pra fintech sebesar 41,72 persen, dengan pertumbuhan terbesar pada 2007 sebesar 98,3 persen dan pada 2005 dan 2004 sebesar 96,9 persen dan 76 persen. Pertumbuhan yang tinggi ini terjadi karena adanya simpati dari masyarakat atas terjadinya bencana alam berupa gempa di Yogya pada 2007 dan Tsunami di Aceh pada 2004 dan 2005. Rata-rata pertumbuhan ZIS pasca fintech sebesar 24,07 persen dengan pertumbuhan tertinggi pada 2016 sebesar 37,46 persen dan terendah pada 2015 sebesar 10,61 persen.

Industri keuangan melakukan inovasi dengan memberikan kemudahan pelayanan di bidang keuangan berupa fintech. Inovasi ini, memberikan pelayanan berupa pembayaran, peminjaman, pembiayaan, perencanaan keuangan, dan investasi yang dilakukan industri keuangan yang berbasis teknologi. Adanya Fintech membuat pelayanan keuangan menjadi cheaper, faster dan clearance. Kesemuanya tidak terlepas dari adanya peran darinya sebagai motor penggerak pertumbuhan e-commerce.

Jumlah penduduk yang banyak yang diikuti dengan semakin banyaknya usia masyarakat yang produktif, serta terjadinya pergeseran status sosial masyarakat merupakan basis pasar yang potensial buat berkembangnya fintech. Investasi global terhadap industri fintech selama 2010 2015 telah mencapai US\$ 49,7 miliar atau setara dengan $\mathrm{Rp} 696$ triliun dengan tingkat pertumbuhan tiga kali lipat setiap tahunnya sejak 2013. Perkembangan fintech di Indonesia akan menggeser e-commerce seiring maraknya penggunaan fintech untuk produk tabungan dan investasi, transfer uang dan pembayaran, peminjaman dan asuransi. Sekjen Asosiasi Fintech Indonesia (AFI), mengungkapkan bahwa penetrasi perbankan yang masih 30 persen, masih kalah jauh dari penetrasi pengguna handphone yang mencapai 130 persen. Sementara itu, penetrasi internet yang sebesar 42 persen, sebagian besar traffic-nya berasal dari mobile. Maka itu, penetrasi perbankan bisa meningkat dengan mobile. Fintech di Indonesia yang masih berupa embrionik, perlu terus melakukan evolusi dengan mencari bentuk yang terbaik.

Pemain fintech di Indonesia ada sebanyak 165 yang 43 persennya bergerak pada sektor pembayaran. Namun, pada 2016 hanya terdapat 36 persen orang dewasa di Indonesia yang memiliki institusi keuangan. Adanya perkembangan teknologi yang pesat akan berdampak pada pertumbuhan fintech.

Gambar 1. Jumlah Perusahaan Fintech di Indonesia pada 2006-2016

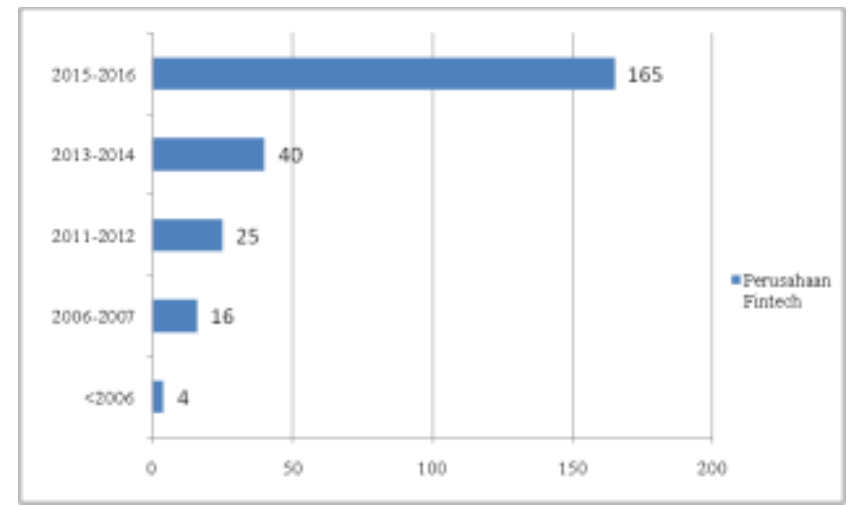

Sumber: Asosiasi Fintech Indonesia dan OJK (2017)

Penggunaan fintech dengan SIMBA terus mengalami pertumbuhan yang pesat. Keadaan ini dapat terlihat dari jumlah pengguna aktifnya terus mengalami peningkatan dari tahun ketahun 
dan begitu juga dengan hits transaksi yang dilakukannya. Rata-rata penggunaan aktifnya selama 2013-2017, rata-rata pertumbuhannya sebesar 81,4 persen dan hits transaksinya sebesar 156,33 persen.

Tabel 1. Jumlah Hits Transaksi dan Pengguna Aktif SIMBA Pada 2013-2017

\begin{tabular}{|r|r|r|}
\hline Year & Transaction Hits & Active Used \\
\hline 2013 & 92552 & 15 \\
\hline 2014 & 110160 & 41 \\
\hline 2015 & 491584 & 60 \\
\hline 2016 & 1541001 & 108 \\
\hline 2017 & 2258772 & 136 \\
\hline
\end{tabular}

Sumber: BAZNAS (Data Diolah)

Penggunaan fintech terbukti sangat membantu pihak yang terkait baik pengelola dan masyarakat. Agar tidak terjadi kejenuhan dari pihak pengguna Fintech, pihak BAZNAS pelu melakukan inovasi teknologi yang lain berupa kerjasama dengan pihak perbankan dan sektor keuangan lain, sehingga pemanfaatan fintechnyanya bukan hanya sampai di tingkat Kabupaten dan Kota tetapi juga ke Desa. Dengan adanya dukungan dari pihak terkait dan masyarakat, diharapkan fintech dapat digunakan untuk mempercepat kesejahteraan umat Islam di Indonesia. Adapun yang menjadi permasalahan dalam penelitian ini adalah bagaimana bentuk trend dari pengumpulan ZIS yang menggunakan fintech dan non fintech, sehingga dapat diprediksi kemungkinan dana yang dapat dikumpulkan, terutama Indonesia yang pada 2025 dinobatkan sebagai negara maju, yang dapat mempercepat kesejahteraan umat Islamnya melalui penggalangan dana ZIS.

\section{Metode Penelitian}

Penelitian ini menggunakan statistik deskriptif, dengan membuat trend linier dan parabola. Data di peroleh dari BAZNAS selama periode 2002-2017 dalam bentuk rasio yakni Rp. Milyar. Adapun prosedurnya dengan melihat trend dari grafik, karena bentuknya dapat linier, parabola, maupun eksponensial. Dari data yang ada kemudian dibuat grafik ternyata terdapat dua bentuk yakni linier dan parabola. Trend linier terjadi pada saat pra penggunan fintech pada 2002-2011 dan trend parabola pada periode selama pengumpulan ZIS sudah mulai penggunaan fintech pada 2002-2017. Digunakan periode 2002-2017 agar trend dari parabola dapat diperoleh lebih smooth. Adapun formula untuk trend linier dan parabola (Anderson et. al., 2019):

Trend Linier dengan menggunakan metode Least square:

$\mathbf{Y}=\mathbf{a}+\mathbf{b X}$

$\mathrm{a}=\frac{\sum \mathrm{Y}}{\mathrm{n}}$

$\mathrm{b}=\frac{\sum \mathrm{XY}}{\sum \mathrm{X}^{2}}$

Trend Parabola dengan menggunakan persamaan:

$\mathrm{Y}=\mathrm{a}+\mathrm{bX}+\mathrm{c} \mathrm{X}^{2}$

$\sum \mathrm{Y}=\mathrm{na}+\mathrm{c} \sum \mathrm{X}^{2}$

$\sum X Y=b \sum X^{2}$

$\sum X^{2} Y=a \sum X^{2}+c \sum X^{4}$

Keterangan:

$\mathrm{Y}=$ Variabel tertentu yang ingin di forecast.

$\mathrm{X}=$ Waktu yang dirubah dalam bentuk skala.

$\mathrm{a}=$ Konstanta yang menunjukkan $\mathrm{Y}$ pada tahun yang dimiliki skala $\mathrm{X}$ sebesar 0 .

$\mathrm{b}=$ Kenaikan atau penurunan nilai $\mathrm{X}$ setiap periode.

$\mathrm{c}=$ Kenaikan atau penurunan nilai $\mathrm{X}$ setiap periode dalam bentuk parabola.

Setelah menggunakan statistik deskriptif dalam bentuk trend kemudian dicari nilainya, lalu diuji dengan menggunakan statisfik inferensia. Sebelum melakukan pengujiannya untuk mengetahui pendekatan dengan menggunakan statistik paremetrik atau non parametrik dengan data rasio, perlu dilakukan uji normalitas, dengan menggunakan one simple kolmogorof smirnof. Apabila nilai signifikansi dari datanya di atas 0,05, maka datanya berdistribusi normal. Dengan adanya data yang berdistribusi normal pengujian dapat menggunakan statistik parametrik, yakni paired sample test (Lind el. al, 2017). Dari perhitungannya apabila nilai signifikansi lebih kecil dari 0,05 maka terdapat perbedaan antara sebelum dan sesudah menggunakan fintech. 


\section{Hasil dan Pembahasan}

Perkembangan penerimaan ZIS pada 200220017 terus mengalami peningkatan. Peningkatan selama 2002-2011 peningkatannya rendah, tetapi pada 2012-2017 peningkatannya tinggi. Keadaan ini, terjadi karena pasca 2012 pengumpulan dana ZIS sudah menggunakan fintech. Pada 2002-2011 terbentuk garis yang berbentuk linier namun pada 2002-2017 terbentuk garis berbentuk parabola. Pasca pengumpulan dana ZIS menggukan fintech diharapkan akan meningkatkan penerimaan ZIS lebih banyak lagi, sehingga kesejahteraan umat Islam dapat lebih pesat. Untuk itu, diperlukan melakukan prediksi agar dapat direncakanan kapan kesejahteraan Umat dapat tercapai, setidaknya pada 2025 diketahui kira-kira jumlah ZIS yang dapat dikumpulkan.

Gambar 2. Jumlah Penerimaan ZIS Menggunakan Fintech dan Non Fintech Pada 2002-2017

(Rp. Milyar)

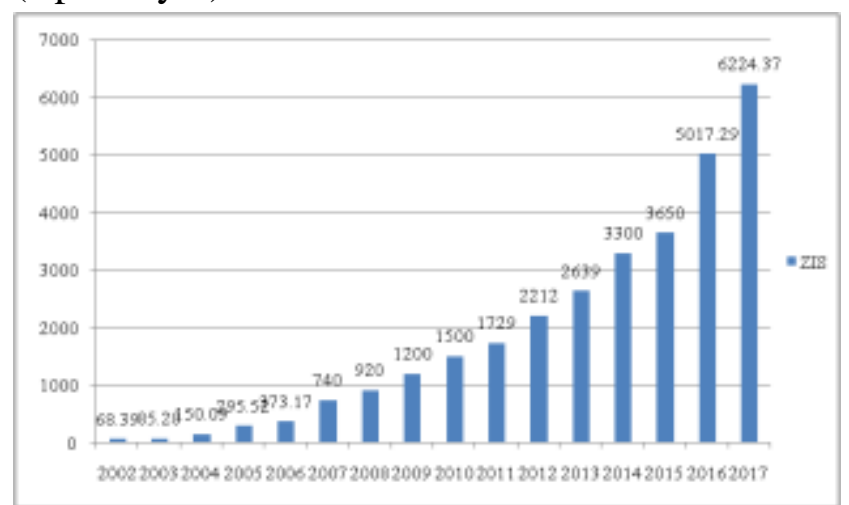

Sumber: Baznas (Data Diolah)

Jumlah penerimaan ZIS dan trend linier pada 2002-2011, memiliki rata-rata yang sama yakni sebesar Rp. 706.15 milyar, dengan jumlah nilai maksimum dan minimum yang sama, yakni pada 2011 dan 2002. .Penerimaan ZIS maksimum sebesar Rp. 1.729 milyar dan minimum sebesar Rp. 68,39 milyar dengan standar deviasi sebesar Rp. 609,93 milyar. Trend linier memiliki nilai maksimum sebesar Rp. 1587,74 milyar dan minimum sebesar minus Rp. 175,45 milyar.
Gambar 3. Jumlah Penerimaan ZIS dan Trend Linier Pada 2002-2011

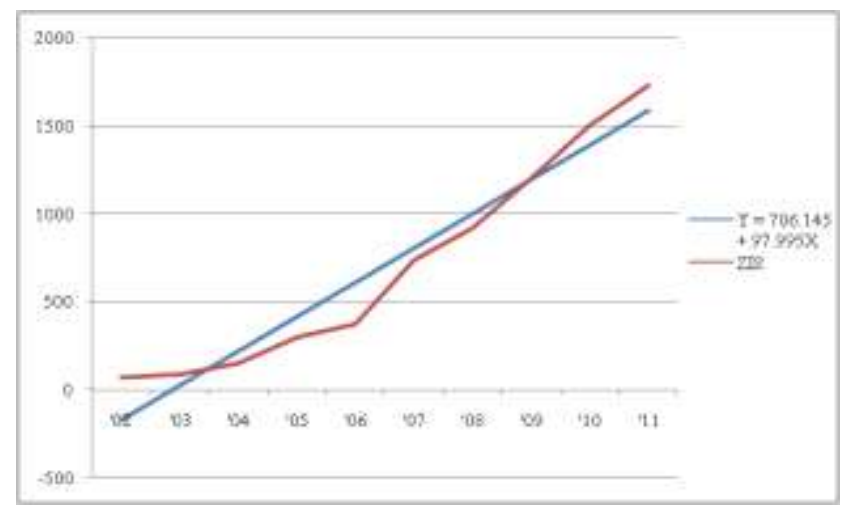

Sumber: Baznas (Data Diolah)

Rata-rata jumlah penerimaan ZIS dan trend parabola pada 2002-2017 sama, yakni sebesar Rp. 1881,51 milyar. Jumlah penerimaan yang tertinggi yang diperoleh ZIS pada 2017 sebesar Rp. 6224,37 milay dan terendah pada 2002 sebesar Rp. 68,39 milyar dengan deviasi standar sebesar Rp. 1856,146 milyar. Trend parabola memperoleh jumlag tertinggi pada 2017 sebesar Rp. 5716,57 milyar dan terendah pada 2004 sebesar Rp. 159,05 milyar, dengan deviasi standar Rp. 1841,18 milyar.

Gambar 4. Jumlah Penerimaan ZIS dan Trend Parabola Pada 2002-2017

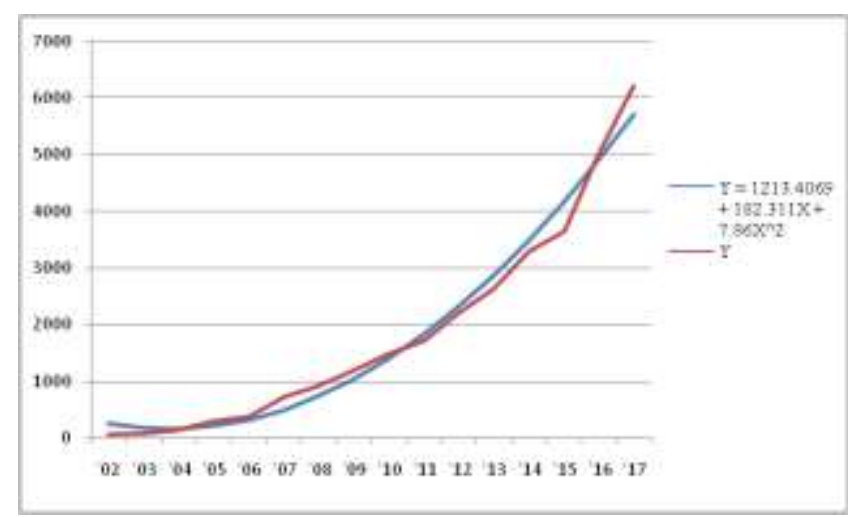

Sumber: Baznas (Data Diolah)

Prediksi jumlah rata-rata penerimaan ZIS menggunakan fintech dan non finteh teradapat selisih sebesar Rp. 2603.55 Milyar, yang besarnya penerimaan fintech sebesar Rp. 4681,44 Milyar dan yang non fintech sebesar Rp. 2077,89 milyar. Penggunaan finteh akan menerima jumlah ZIS terebesar pada 2025 sebanyak 14.418,51 milyar dan terendah pada 
2004 sebanyak 159,05. Non fintech menerima jumlah terbesar pada 2025 sebanyak 4330,48 dan terendah pada 2002 sebanyak minus 175,45.

Gambar 5. Prediksi Jumlah Penerimaan ZIS Menggunakan Fintech dan Non Fintech Pada 2002-2025

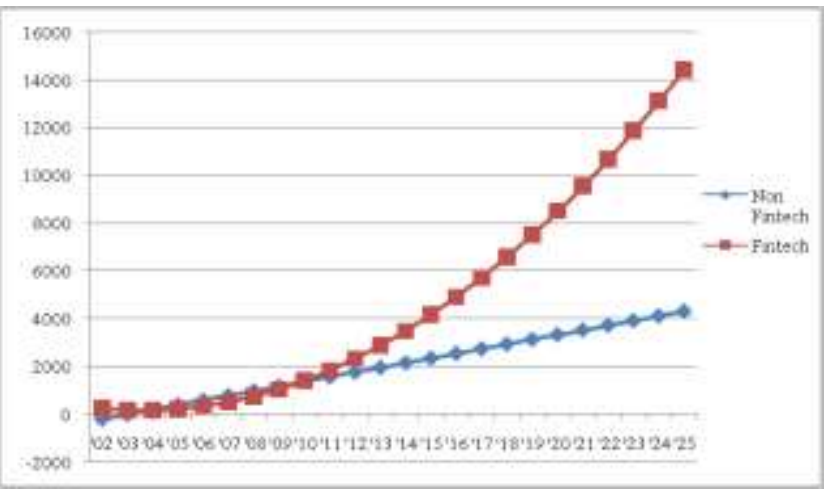

Sumber: Baznas (Data Diolah)

Prediksi rata-rata dari pertumbuhan pengumpulan dana ZIS pada 2018-2025 dengan menggunakan fintech lebih besar dari pada non fintech. Rata-rata pertumbuhan penerimaan ZIS dengan Fintech sebesar 9,98 persen dan non fintech sebesar 5,78 persen. Penggunaan fintech akan meningkatkan pertumbuhan penerimaan ZIS maksimum pada 2018 sebesar 15,18 persen dan terendah pada 2025 sebesar 9,98 persen. Non fintech pertumbuhan penerimaan ZIS maksimum sebesar 7,09 persen pada 2018 dan minimum sebesar 4,74 persen pada 2025 .

Gambar 6. Pertumbuhan Penerimaan ZIS Menggunakan Fintech dan Non Fintech Pada 2018-2025

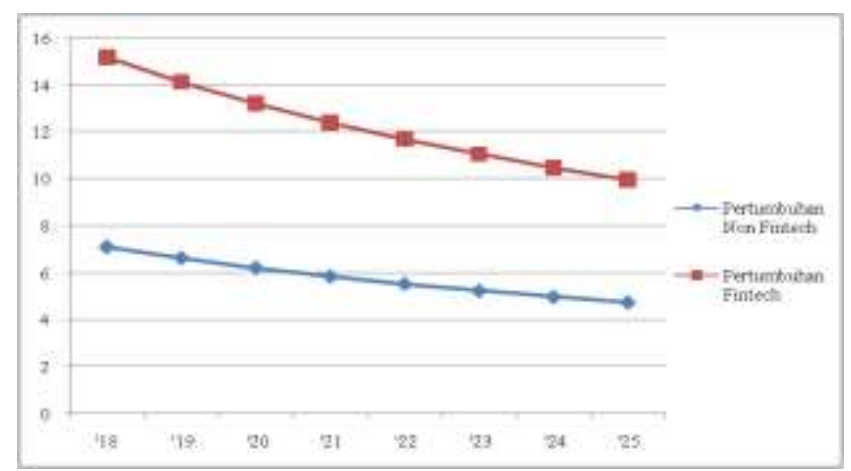

Sumber: Baznas (Data Diolah)

Setelah dilakukan prediksi periode 20022025 untuk yang fintech dan non fintech kemudian dilakukan uji normalitas dengan menggunakan one simple kolmogorof smirnof. Adapun hasilnya adalah dari data prediksi fintech dan non fintech berdistribusi normal, karena signifikansi keduanya diatas 0,05, yakni 0,200>0,05 untuk Non Fintech dan 0,109>0,05 untuk Fintech.

Tabel 2. Hasil Uji Normalitas

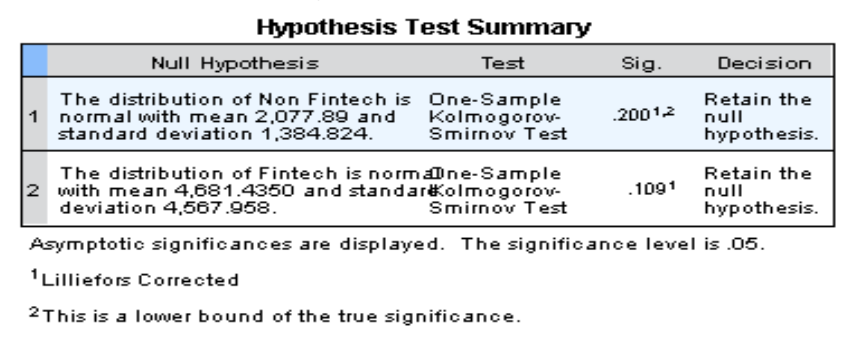

Hasil dari uji normalitas dari fintech dan non fintech berdistribusi normal dapat digunakan uji statistik parametrik. Uji yang digunakan dalam penelitian ini adalah paired sample test, karena dengan uji beda dua sampel berpasangan dapat diketahui bagaimana bila subjek yang digunakan sama tetapi mengalami perlakuan yang berbeda, yakni pengumpulan ZIS dengan fintech dan non fintech. Adapun hasil pengujian menunjukkan bahwa korelasi antara non fintech dan fintech sebesar 0,954 dengan signifikansi sebesar 0.0000 . Hasil ini menunjukkan bahwa terdapat korelasi antara dua rata-rata penerimaan ZIS menggunakan fintech dan non fintech adalah kuat dan signifikan.

Tabel 3. Hasil Uji Correlations

Paired Samples Correlations

\begin{tabular}{ll|c|c|c}
\hline & $\mathrm{N}$ & Correlation & Sig. \\
\hline Pair 1 & $\begin{array}{l}\text { Non Fintech } \\
\text { \& Fintech }\end{array}$ & 24 & .954 & .000 \\
\hline
\end{tabular}

Sumber: Baznas(Data diolah)

Hasil dari uji hipotesis paired sample test dengan nilai t hitung sebesar minus 3.896 dengan signifikansi 0,001. Dari hasil uji hipotesis diperoleh signifikansi lebih kecil dari pada 0,05 , yakni $0,001<0,005$, dapat disimpulkan bahwa rata-rata penerimaan ZIS menggunakan sebelum dan sesuadah menggunakan fintech adalah tidak sama (berbeda). Artinya, bahwa dengan penggunaan fintech akan mempengaruhi jumlah penerimaan ZIS. 
Tabel 4. Hasil Uji T

Paired Samples Test

\begin{tabular}{c|c|c|c|c|c|}
\hline & \multicolumn{2}{|l|}{ Paired Differences } & \multirow{2}{*}{$\mathrm{t}$} & df \\
\cline { 2 - 4 } & Mean & $\begin{array}{c}\text { Std. } \\
\text { Deviation }\end{array}$ & $\begin{array}{c}\text { Std. Error } \\
\text { Mean }\end{array}$ & t \\
\hline
\end{tabular}

\begin{tabular}{l|l|l|l|l|l|l}
\hline Pair 1 Non & -2603.545 & 3273.628 & 668.2264 & -3.896 & 23
\end{tabular} FintechFintech

Sumber: Baznas (Data Diolah)

Pemenfaatan fintech akan mempermudah dan memperlancar BAZNAS dalam mengumpulkan dana umat, karena memiliki multiplier effect yang lebih besar karena memiligi garis trend yang berbentuk parabola. Untuk itu, agar dapat mempercepat kesejahteraan umat BAZNAS dan masyarakat perlu lebih lebih mengoptimalakan dalam pemanfaatan fintech.

\section{Kesimpulan}

Penerimaan ZIS menggunakan fintech dan non fintech terdapat korelasi yang kuat dan signifikan. Dengan demikian, rata-rata penerimaan ZIS sebelum dan sesudah menggunakan Fintech adalah tidak sama (berbeda). Artinya, bahwa dengan penggunaan Fintech akan mempengaruhi jumlah penerimaan ZIS. Prediksi rata-rata dari pertumbuhan pengumpulan dana ZIS pada 2018-2025 dengan menggunakan fintech lebih besar dari pada non fintech. Rata-rata pertumbuhan penerimaan ZIS dengan fintech sebesar 9,98 persen dan non fintech sebesar 5,78 persen. Pihak BAZNAZ sebaiknya tetap meningkatkan penggunaan fintech dengan cara melakukan kerjasma dengan berbagai institusi baik keuangan maupun non keuangan dan sekaligus melakukan sosialisasi pemanfaatan fintech terhadap masyarakat dalam mengelola ZIS. Penggunaan fintech diharapkan pertumbuhan penerimaan ZIS dapat lebih pesat lagi sehingga penurunan pertumbuhannya menjadi lebih lambat bahkan diharapkan trendnya dapat berbentuk eksponensial, sehingga kemaslahatan umat Islam dapat segera diatasai.

\section{Daftar Pustaka}

Anderson, David R., Dennis J. Sweeney, Thomas A. Williams, Jeffrey D. Camm, James J. Sig.Cochran. 2019. Statistics for Business \& (2-tailqdenomics. Cengage Learning.

B.001

Buarque, Christofam. 1993. The End of Economics: Ethics and Disorter of Progress. London, Zed Books.

Chapra, M. Umar. 2001. Whats is Islamic Economics. Jeddah: IRTI-IDB.

Hamilton, Clive. 1994. The Mystic Economist. Australia, Hamilton.

Karim, Adiwarman A. dan A. Azhar Syarief. 2009. Fenomena Unik di Balik Menjamurnya LAZ (Lembaga Amil Zakat) di Indonesia. Jurnal Pemikiran dan Gagasan, Vol. 1.

Lind, Douglas A., William G. Marchal, Samuel A. Wathen. 2017. Statistical Techniques in Business and Economics. McGraw-hill.

McKeon, R. and Weir, T. 2000. Towards KBEs: Preconditions and Assessments. Paper for APEC Symposium on Knowledge-based economies. Seoul, 29-30 June.

Marimin, Agus dan Tira Nur Fitria. 2015. Zakat Profesi (Zakat Penghasilan) Menurut Islam. Jurnal Ilmiah Ekonomi Islam. Vol. 1(1).

Marzuki, Angga dan Ibnu Qomar. 2015. Arah Baru Kebijakan Publik: Studi Kasus Pember-dayaan Zakat. Jurnal Bimas Islam Vol. 8(4).

Rothchild, Kurt W. 1993. Ethics and Economic Theory. Cambride: Edward Elgar.

Romdhoni, Abdul Haris. 2017. Zakat Dalam Mendorong Pertumbuhan Ekonomi dan Pengentasan Kemiskinan. Jurnal Ilmiah Ekonomi Islam. Vol. 3(1).

Rahmawati, Yuke. 2011. Refleksi Sistem Distribusi Syariah Pada Lembaga Zakat dan Wakaf Dalam Perekonomian Indonesia. AlIqtishad. Vol. 3(1).

Soekapdjo, Soeharjoto., Lucky Nugroho, Ahmad Badawi, Wiwik Utami. 2018. Bad debt issues in Islamic bank: macro and micro influencing (Indonesia cases). International Journal of Commerce and Finance. Vol. 4(1). 
Jurnal Ilmiah Ekonomi Islam, 5(02), 2019, 144

Soeharjoto. 2016. Pengaruh Penanaman Modal Asing dan Daya Saing Terhadap Ekspor Industri Manufaktur di Indonesia. Media Ekonomi. Vol. 24(2).

Undang-undang Republik Indonesia Nomor 23 Tahun 2011 tentang Pengelolaan Zakat.

Undang-undang Republik Indonesia Nomor 38 Tahun 1999 tentang Pengelolaan Zakat.

Undang-undang Republik Indonesia Nomor 14 tahun 2008 tentang Keterbukaan Informasi.
Walter, Leimgruber. 2004. Between Global and Local. Aldershot (England): Ashgate Publishing Limited.

Wahyuni, Eka Tri dan Aprina Chintya. 2017. Pembagian Zakat Fitral Kepada Mustahiq: Studi Komparatif Ketentuan Asnaf Menurut Imam Syafi'i dan Imam Malik. Muqtasid. Vol. 8(2).

www.simba.baznas.go.id

www.basnaz.go.id

www.fintech.id

www.ojk.go.id 